\title{
Um certo conceito de
}

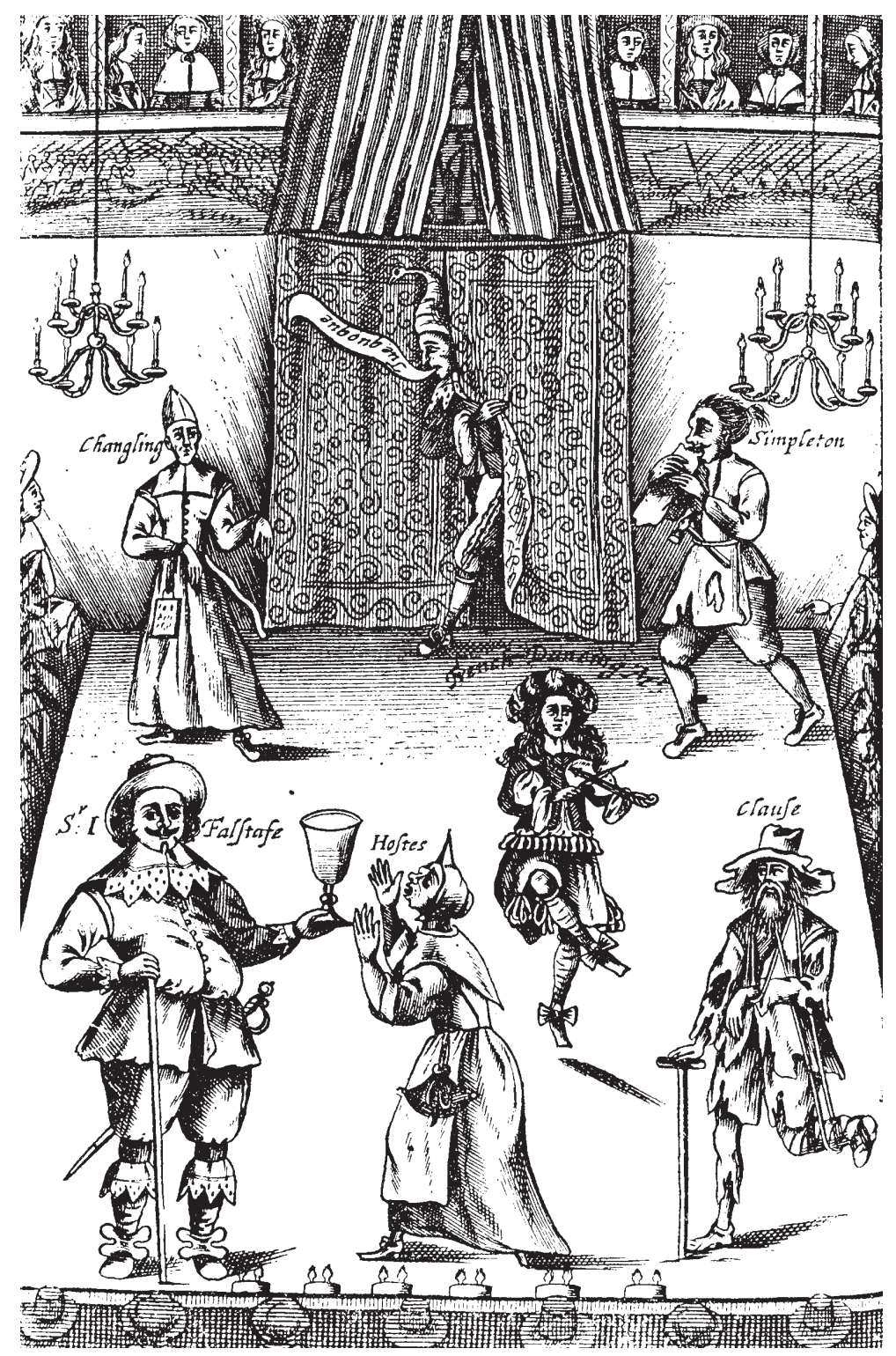

SÉRGIO DE CARVALHO

é professor de Literatura

Dramática do

Departamento de Artes

Cênicas da Unicamp,

diretor e dramaturgo da

Companhia do Latão, e

editor da revista Vintém.

História Mundial do

Teatro, de Margot

Berthold, São Paulo,

Perspectiva, 2000.

Ilustração de

1672 para livro de Francis

Kirkman
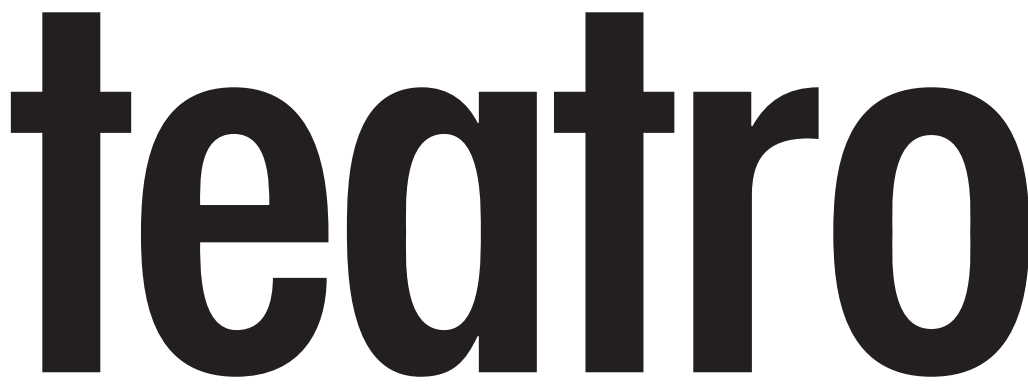


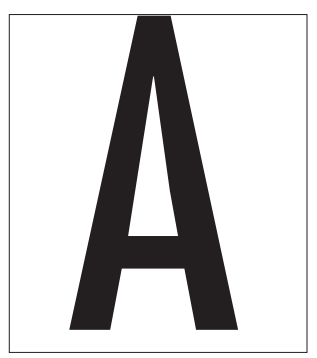

História Mundial do Teatro, de Margot Berthold, é dos poucos livros desse tipo lançados no Brasil. Na década passada tivemos, salvo engano, apenas uma publicação semelhante, Teorias do Teatro, de Marvin Carlson, que, como o nome diz, dá um panorama das teorias cênicas e dramatúrgicas desde Aristóteles, mas sem o propósito de descrever as práticas do palco. Quem procurar nas prateleiras dos sebos paulistas outras historiografias gerais só encontrará, com muito esforço, algumas das tentativas brasileiras, escritas para atender a necessidades imediatas de sala de aula (penso nos trabalhos de Hermilo Borba Filho e Nélson de Araújo), com um propósito quase heróico de estabelecer sínteses pedagógicas para uma “fertilização intelectual”, e que, tendência comum ao conjunto do nosso teatro, se mostraram como ações sem continuidade. Quanto aos grandes compêndios estrangeiros, como a História do Teatro Dramático, do italiano Silvio D'Amico, ou a História do Teatro Europeu, do russo Ignatov, refe-

\section{Xilogravura}

para a edição

de uma comédia

de Terêncio

(1561) rências clássicas do século XX, escritas em mais de um tomo, ao certo ainda causam nos nossos editores algum temor pânico de encalhe, única explicação para lacunas tão notáveis.

Uma segunda virtude da História Mundial do Teatro, de Margot Berthold, virtu-

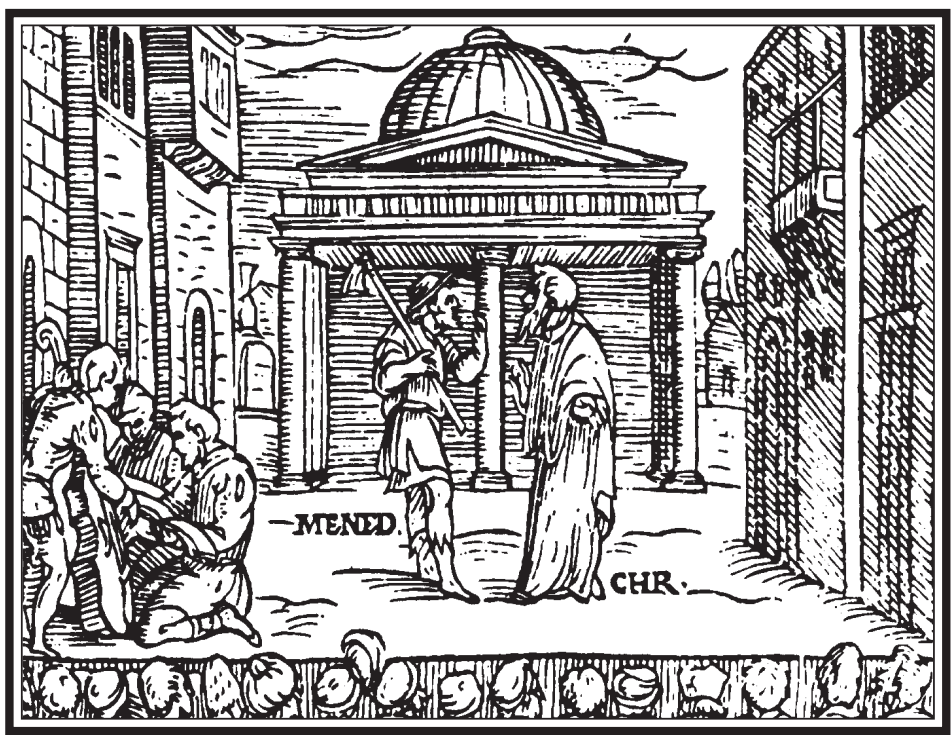

de já interna, está na abrangência de seu plano. É um livro em que o termo "mundial" do título não decorre de uma megalomania européia, mas do propósito de dispor, em pé de igualdade, sem hierarquia, várias formas representacionais do Ocidente e de civilizações antigas, como as dos egípcios, chineses, indianos, persas, sem que as produções populares sejam consideradas menos importantes do que as eruditas, sem que as teatralidades orientais sejam lidas como preparatórias do "milagre" teatral grego.

Ainda que a autora tenha como referência um certo conceito discutível de teatro, que se liga, sim, à forma dialogada, à imbricação com a vida pública da cidade e ao aparecimento do ponto de vista do indivíduo, estas referências, determinantes na experiência grega, são pouco utilizadas como critérios explícitos de valor. Surgem de passagem, como comentários paralelos, e mais interferem no conjunto de uma seleção que, ao fim das contas, escolheu mostrar as representações das grandes civilizações, e não as das culturas localizadas.

Fica valendo, de qualquer modo, o dito de Ariano Suassuna, segundo o qual, "o Teatronãocomeça na Grécia, é o teatro grego que começa na Grécia”, neste livro que tem um gosto mais universal do que a média.

Como decorrência do respeito pelas formas tradicionais, surge mais uma virtude do trabalho. Refiro-me à sua atenção aos materiais concretos da cena, aos problemas de ordem sensível do palco, coisas que os artistas (e não os críticos) costumam manipular no seu ofício. De cada página fica antes a visualização dos espetáculos do que a dos textos. Fica a imagem das formas arquitetônicas dos espaços e das construções cenográficas.

Vez ou outra, despontam os limites desta escolha. Estimulado pelos relatos históricos, o leitor sente falta de uma reflexão que consiga integrar o modo de produção, a circunstância e o projeto artístico. O que não veda, porém, a quem se dispuser a tanto, a possibilidade de expandir as breves sugestões em busca de uma interpretação crítica mais aprofundada. 
Cabe lembrar que é uma obra publicada originalmente em 1968. Sua construção algo fenomenológica parece se nortear por uma tentativa de síntese cultural, em que o pensamento procura abrir espaço à descrição dos modos teatrais particulares. Essa fascinação pelos gêneros segue a tradição do idealismo humanista alemão, mas corresponde também ao preceito de deixar as “obras falarem" com base em seus pressupostos mais gerais, sem intenção de interpretação crítica. Se compararmos tal perspectiva, ainda totalizante (em que pesem suas mediações panorâmicas), com as especializações e fragmentações dos estudos teatrais a partir dos anos 70, que passaram a se debruçar sobre as matemáticas semiológicas, as linguagens abstraídas da história ou sobre particularizações étnicas, regionais e arcaicas, a ponto de abrirem mão, de vez, do problema do valor (que assim passou a ficar ocultamente dado, sem mais necessidade de ser construído pelo argumento, num vale-tudo poético muitas vezes paralisante), não tenho dúvidas em afirmar que o "idealismo sensível" da autora alemã, com sua saudade de Goethe e Schiller, tinha maior utilidade.

Recolhido logo da segunda página do livro, o seguinte parágrafo nos serve de ponto de partida para discutir melhor o enquadramento conceitual com base noqual ela trabalha. Ao falar das características dos teatros primitivos, escreve: "O desenvolvimento e a harmonização do drama e do teatro demandam forças criativas que fomentem o seu crescimento; é também necessária uma auto-afirmação urbana por parte do indivíduo, junto a uma superestrutura metafísica. Sempre que essas condições foram preenchidas seguiu-se um florescimento do teatro".

\section{O FLORESCIMENTO DO TEATRO}

Dessa asserção, surgem várias questões polêmicas. A primeira se refere aos conceitos de "teatro" e "drama", apresentados como distintos, o que de fato são - ainda que a tradição anglo-americana os identifique -, mas cujo suposto padrão ideal seria o de uma harmonização. Não é demérito para ninguém acreditar que o "teatro dramático" é um estágio superior da arte da representação, ainda que isso não seja verdade. Hegel partilhou dessa auto-referente convicção que só pode ser compreendida na perspectiva da visão de mundo burguesa, e na afinidade de seu próprio sistema filosófico com os dialogismos teleológicos do drama. Como forma literária particular, no entanto, o "drama” é datado, com história precisa, correlato ao fortalecimento dos valores libertários do indivíduo moderno e à ascensão da burguesia como classe.

Não é o "drama burguês" que Margot Berthold tem em mente no citado parágrafo, mas parece que os valores desta forma histórica impregnam sua proposição de um conceito geral, o que também já acontecia com as teorias novecentistas que, retomando Platão e Aristóteles, estabeleceram as distinções com o épico e o lírico.

O “drama” geral, que ela apresenta como inegável conquista civilizatória, corresponde a uma forma teatral e literária em que existe um dualismo da voz narrativa, instaurado, no caso grego, pelo respondedor do coro, divisão que fez com que a palavra não proviesse de um narrador, mas fosse gerada pelos diversos agentes da ação representada. Acredito que seja com esta idéia que ela trabalha.

Já o conceito de teatro a que ela se refere parece sugerir toda e qualquer organização espetacular com intenção estética evidente. Uma dança ritual indígena ou um canto invocatório, por exemplo, seriam formas que "carregam em si as sementes do teatro", mas que não podem ser lidas com os mesmos parâmetros. As eventuais qualidades estéticas não estão em primeiro plano por não haver um público que as perceba como tais. Dirá a autora: “O componente decisivo do teatro: seu indispensável parceiro criativo, o público", é quem define a relação com a obra. Além disso, a comunhão ritual não é coisa a que se chegue pelo debate consciente, pelas oposições dialógicas que constituirão o “drama”. As 
práticas da religiosidade, mesmo que cheguem a demonstrar (em termos adjetivos), alguma "dramaticidade" ou "teatralidade", se encontram tão distantes do "teatro" ou do "drama" (em termos substantivos) quanto mais próximas de uma força epifânica que porventura tenham.

Essas antinomias são importantes para a leitura do livro. Reaparecem em várias passagens, como no capítulo do teatro medieval bizantino, em que um dos tópicos se intitula "teatro sem drama".

Ali fica nítida uma modificação na liturgia da Igreja Oriental, que, em determinado momento, assumiu um caráter dramático, "com suas recitações alternadas, hinos cantados por um solista e coros respondentes, sermões dos dias festivos e diálogos intercalados". O dualismo se instaura na cerimônia, como etapa da superação simbólica em Deus. O ritual assume qualidade dramática. São, entretanto, modos de organizar o ofício religioso que não modificam, no todo, a atitude do participante, a ponto de termos diante dos olhos um espetáculo de teatro. Mais adiante, quando as representações ganham autonomia ficcional, como histórias mostradas nas adjacências da celebração, aí sim surgem as formas teatrais. Pelo caráter específico da cultura bizantina naquele momento de declínio do Império Romano e da ascensão do cristianismo, uma certa rarefação da cidadania parece ter favorecido a proliferação de diversas teatralidades de cunho religioso. Mesmo ligadas ao âmbito de um culto que se dramatizava, não chegaram a derivar em teatros dramáticos, coisa que a autora parece lamentar.

As relações entre teatro e religião perfazem um dos temas mais importantes de qualquer história do teatro. O interesse em distinguir em teoria experiências que têm fronteiras práticas comuns está em entender os mecanismos culturais próprios com que cada época e lugar, para além de comemorar os deuses, passaram a refletir sobre o sentido das ações humanas.

No cristianismo ocidental da Idade Média, por exemplo, as representações da Paixão de Cristo, ocorridas nas festivida- des da Páscoa, tinham, em cada localidade, as feições da comunidade. Mas seguiram uma dinâmica invariavelmente comum às situações de fortalecimento urbano: de início mostradas dentro da nave da Igreja, foram para o pátio próximo à porta principal, depois se espraiando pelas ruas e praças públicas. Um movimento que parece provir de uma necessidade de propaganda religiosa aliada aos interesses da pequena burguesia das corporações de ofício em ascensão, que patrocinavam os festejos também para se ver neles representada. Talvez a interferência tenha sido responsável pela gradual modificação “dramática” de certas cenas dos Passos de Cristo, cujo exemplo mais curioso do livro é o do crescimento de personagens secundárias ligadas à vida urbana, tipos como aquela mulher do ferreiro que, diante da hesitação do marido em vender aos legionários romanos pregos para o martírio da crucificação, ela mesma toma da tenaz e do martelo para forjar as peças. $\mathrm{O}$ teatro, ao longo de sua história, tem sido um espaço privilegiado pelo qual as classes dominantes ou ascendentes reconhecem e fortalecem sua imagem pública.

É na mesma linha de raciocínio que vale chamar a atenção ao destaque dado por Margot Berthold à noção de "superestrutura metafísica”, que, se contraposta à “autoafirmação urbana por parte do indivíduo", favoreceria o florescimento do teatro dramático.

A interferência da "superestrutura metafísica" nas formas de representaçãoé uma hipótese que tem validade relativa só até o Renascimento. A partir da era burguesa tem relevância teórica se discutida do ponto de vista do gosto poético. É o que ela faz, sem que isso fique muito claro. Não é como proposição científica que a autora se permite encerrar seu estudo com a seguinte idéia, exposta nas últimas páginas do livro: “O teatro, quando alcança a perfeição, é igualmente a mais antiga e a mais contemporânea representação da vulnerabilidade do homem diante de forças inescrutáveis".

Como doutrina poética tem lá sua beleza. As angústias do homem em relação à morte, ou qualquer nome que se dê a este 


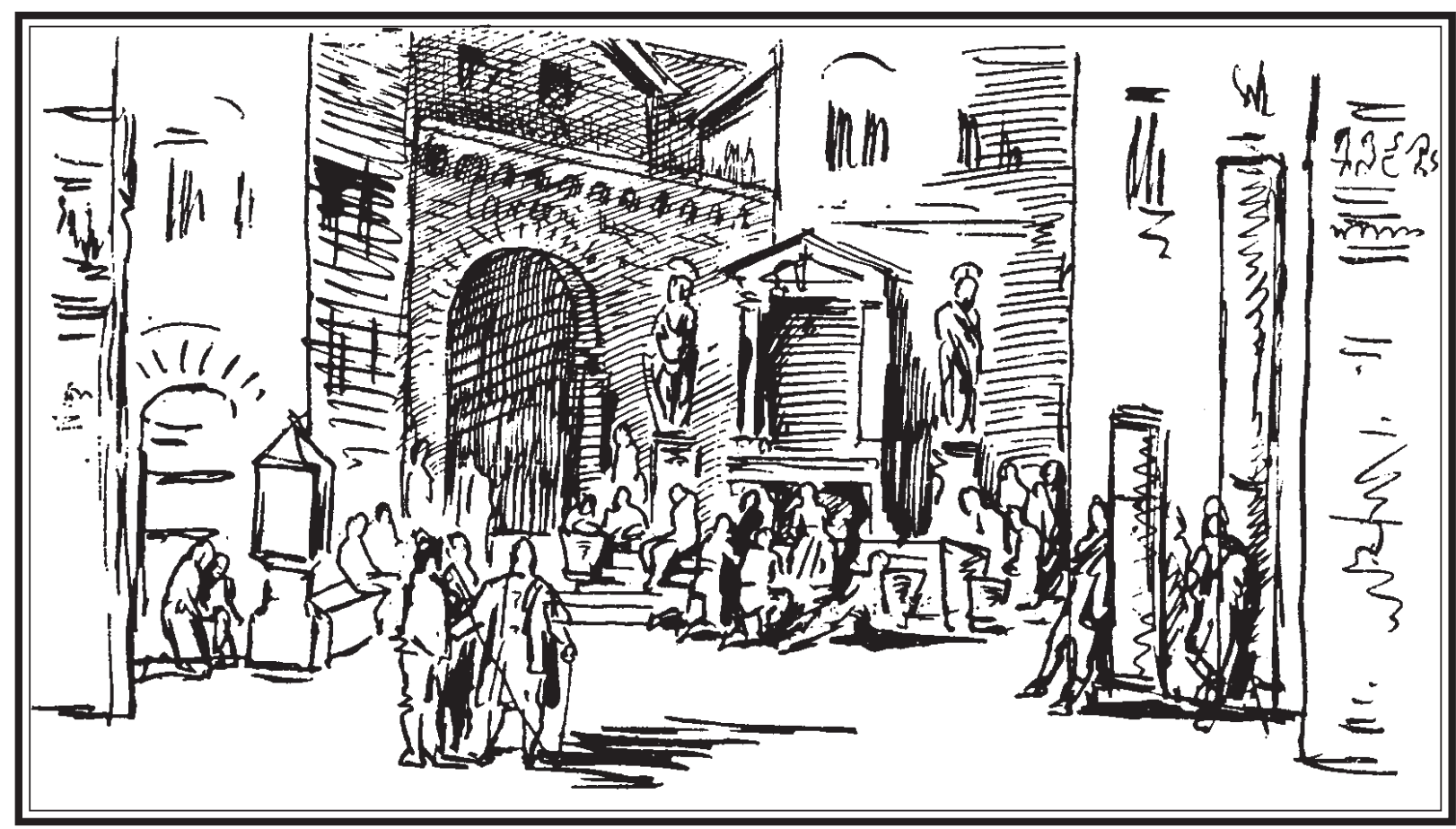

campo de preocupações, constituem um tema de alcance universal na história do teatro. E não seria difícil achar quem traduzisse a expressão “forças inescrutáveis" por "mundo administrado" ou qualquer correlato politizante. Isso não nos impede de lembrar que se trata de uma visão específica de arte, que não contém em si todas as possibilidades dela, nem necessariamente as mais importantes.

Acredito que o fator mais importante para o "florescimento do teatro", por seu poder de desestabilização, está naquilo que a própria autora denomina "forças criativas". Mais uma vez, ela não define a expressão. Ao certo se refere a uma inter-relação de interesses entre artistas e público em determinada época. São demandas advindas das vontades coletivas que podem explicar, caso a caso, as enormes interferências mundanas nesse diálogo com as “forças inescrutáveis". É muitas vezes a necessidade de compreender a totalidade das experiências do público que pede o atrito entre a visão trágica da vida e a visão cômica. O fenômeno teatral é, no mínimo, tão complexo como sugere a seguinte passagem: "Em todos os lugares e épocas, o teatro incorporou tanto a bufonaria grotesca quanto a severidade ritual. Podemos en- contrar elementos farsescos nas formas mais primitivas".

A leitura da História Mundial do Teatro também parece sugerir, nas entrelinhas, que o teatro, considerado apenas como espetáculo sensível, quando desvinculado de seus debates verbais, teria maior aptidão a ser instrumentalizado por forças conservadoras. Nos termos da autora, o "teatro" sem "drama" tenderia a ser menos problematizador, menos rebelde, mais conformista do que o "dramático", e acredito que essa hipótese polêmica não deve ser descartada de imediato. De fato, os grandes impérios foram mais "espetaculares" do que “dialogantes”, como se vê na Roma colonizadora, que precisava levar, aos quatro cantos do mundo, uma mistura de distração popular e imagem venerável de governo central. Não era tarefa que solicitasse divergências retóricas, como bem sabiam aqueles que se utilizaram do circo como aliado forte, não apenas para motivar e distrair os exércitos no meio dos povos conquistados, mas também para transmitir a impressão de insuperáveis avanços modernizantes aos dominados. As demonstrações tecnológicas dos aparatos mecânicos, das cenografias mirabolantes eram sobretudo uma afirmação do poderio romano. Se pen-
Desenho de cenário para uma peça de Julius Minding (1873) 
sarmos no que vem ocorrendo com a difusão tecnológica da cultura artística norteamericana, encontraremos analogias reveladoras.

O que não se pode, a partir daí, é confiar na opção contrária de que o impulso “dramático" - com suas crises verbais - se associa, em geral, a um espírito de rebelião, como está sugerido no seguinte trecho acerca das práticas egípcias: "Para um florescimento das artes dramáticas, teria sido necessário o desenvolvimento de um indivíduo livremente responsável que tivesse participação na vida da comunidade, tal como encorajado na democrática Atenas. Faltava ao egípcio o impulso para a rebelião, não conhecia o conflito entre a vontade do homem e a vontade dos deuses, de onde brota a semente do drama".

Apesar de uma admiração tipicamente moderna pela teatralidade do Oriente, o que vibra no fundo de tal opinião é, de novo, a valorização da idéia de que o "teatro dramático" tem alguma supremacia por expressar o ponto de vista do indivíduo. Para usar o da autora: "O drama se desenvolve a partir do conflito simbolizado na idéia dos deuses transposta para a psicologia humana".
O que precisa ficar claro é que o "drama" não é uma mágica modificação do ritual, mas sim uma nova possibilidade histórica de teatro entre tantas outras. Quando o coro grego se divide, o drama não nasce do rito, mas sim uma nova forma de teatro se diferencia de outra anterior, que já vinha sendo praticada como manifestação estética, parte de uma festividade, essa sim, religiosa. É neste sentido que a valorização das teatralidades do indivíduo, ainda mais se consideradas por seus aspectos "psicológicos", deve ser entendida como doutrina. Quase sempre as afirmações gerais sobre o teatro ocultam sua real face de norma poética.

Não se pode atribuir virtude ontológica a nenhuma forma ou projeto artístico desvinculado de seu contexto histórico. Nem ao "teatro", nem ao "drama”, seja lá o que signifiquem esses termos que se tornaram objeto de interesse especulativo a partir do Renascimento, e que estiveram em questão sempre que um grupo esteve preocupado em definir historicamente sua visão de cultura, ao mesmo tempo em que se reconhecia como grupo em busca de hegemonia. Exemplo disso é a trajetória dos projetos modernos de formação dos

Cena de

Opere Varie de

A. Manzoni

(1845)

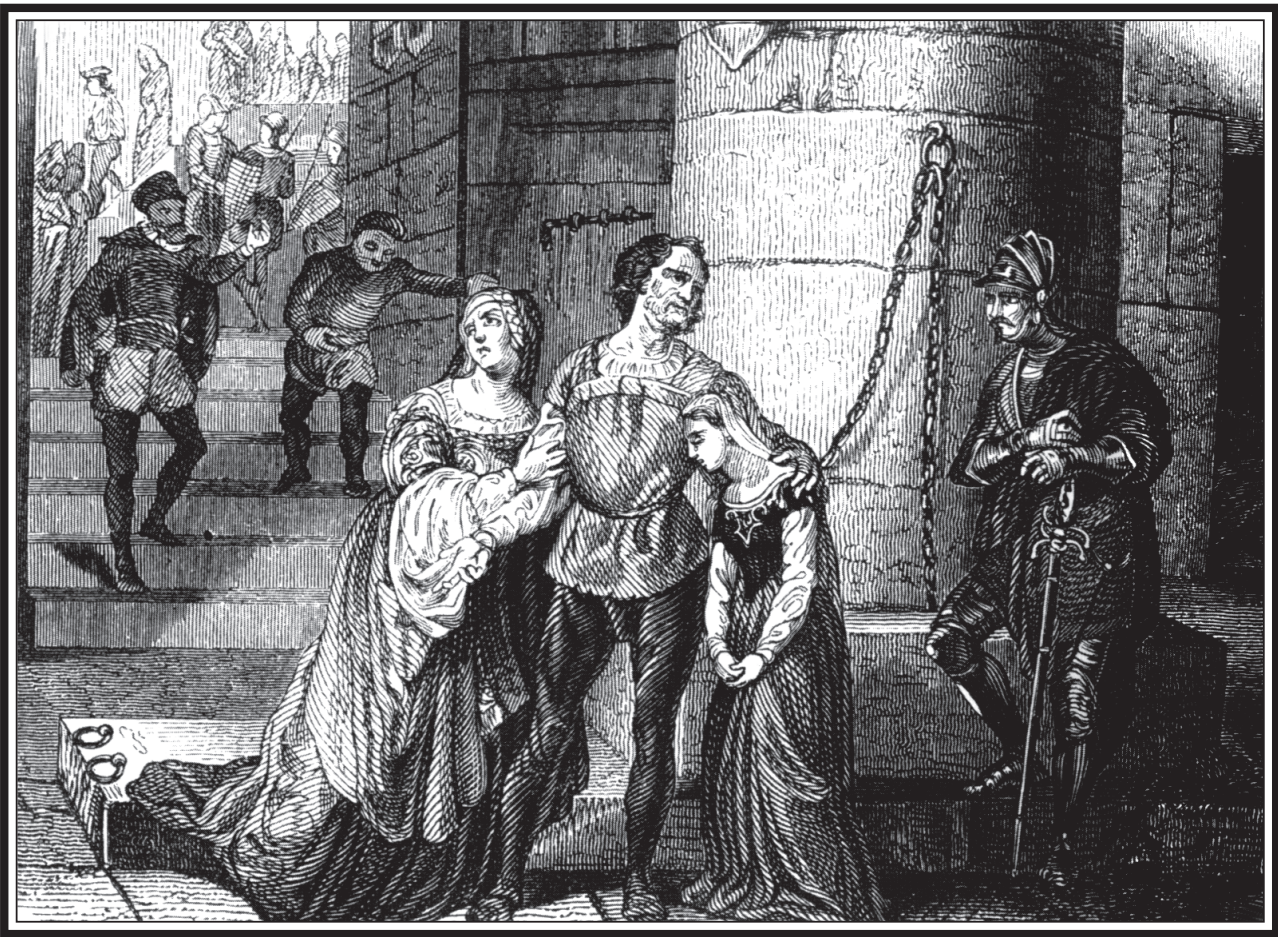


teatros nacionais europeus, que, entre os séculos XVII e XIX, caminharam de um "racionalismo ilustrado para um pobre nacionalismo burguês”. O resultado prático, no conjunto da cultura, foi uma gradativa naturalização de ideais particulares, que aparecem como valores gerais da humanidade. Mesmo aqueles que almejaram de fato um projeto mais universalista, como Goethe ou Schlegel, acabaram por esbarrar na incapacidade concreta de construir meios para que a Ilustração pudesse ser levada ao conjunto da sociedade.

As complexas relações entre ideologia dominante e formas artísticas não se explicam facilmente por meio de relações causais. A indeterminabilidade, porém, não invalida o exame das mútuas influências e intenções manifestas. Este ponto merece especial atenção no caso brasileiro. A dificuldade histórica da burguesia nacional em se reconhecer como classe deita raízes numa sociabilidade marcada, ao menos até o século XIX, por precários sistemas representativos e pela vigência de relações de dependência, compadrio, caudilhismo, que resultaram numa histórica hipertrofia do poder privado dos grupos familiares e numa fraqueza do poder público. Esses fatores desintegradores das representações políticas indefiniram também as representações simbólicas. Temos no Brasil contraditórias formas teatrais, entretecidas de idealismos burgueses (que nos chegavam na velocidade dos avanços do capitalismo internacional) mas que não se tornaram por aqui matérias da ação das peças. Nos momentos em que tentamos os nossos projetos nacionalistas, tanto no Romantismo, como no Modernismo, épocas em que aflorou a pergunta sobre qual seria nossa teatralidade própria, mesmo aqueles que acreditaram ser preciso representar a vida dos tipos nacionais não chegaram a criar narrativas em que a história decorresse de ações responsáveis de indivíduos livres. A liberdade parece ter sempre sido uma experiência retórica no teatro nacional. E o drama burguês foi uma meta com freqüência desejada e nunca alcançada. Nossas mediações formais mais paradigmáticas costumam ser

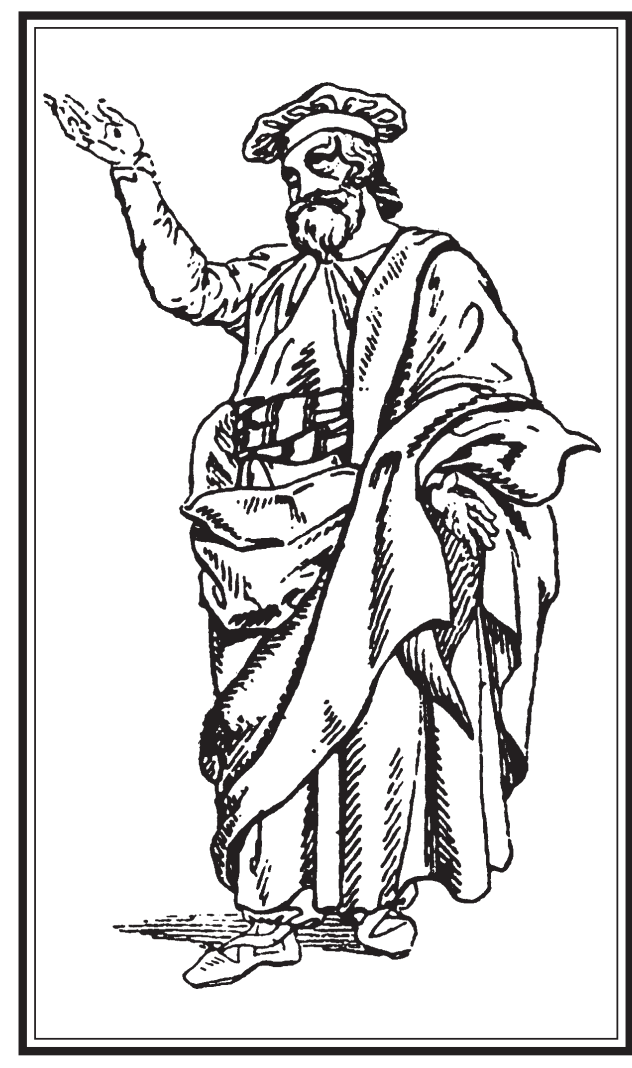

Água-forte dos Irmãos

Henschel para uma peça de Lessing (1811) feitas de fora da obra, em esquemas genéricos que tentam harmonizar diferenças que não surgem como enfrentamento. Quando entendermos melhor o processo de autoconstituição da nossa burguesia como classe, talvez possamos compreender as contradições de tentativas teatrais de modernização que, todavia, parecem nunca superar uma difusa vontade de transformar a comunidade em “comunhão”, ambição típica da mentalidade clânica.

Encerro este comentário pensando que nunca se fez teatro sem que estivesse em questão a função da atividade. Uma das virtudes práticas desta arte tem sido sua capacidade de escancarar, pela imediatitude do fenômeno, as contradições que a constituem. A cena não esconde nada porque seus meios de dizer e mostrar o mundo estão, por mais que se tente ocultá-los, expostos. Só um pacto ideológico permite o logro. O teatro é um lugar de estranheza, e por isso a história do teatro pode ser lida como a história de seu funcionamento interessado. Por mais de um motivo, este livro nos faz pensar nisso, no teatro como coisa estranhável. 